\title{
Nephroprotective activity of Annona Squamosa leaves against paracetamol- induced nephrotoxicity in rats: in vitro and in vivo experiments
}

\author{
S. Neelima ${ }^{1 *}$ D, P. Dwarakanadha Reddy ${ }^{2}$ and Chandra Sekhar Kothapalli Bannoth ${ }^{3}$
}

\begin{abstract}
Background: Paracetamol (PCM), being extensively adapted analgesic and anti-inflammatory drug all over the world, beyond therapeutic dosages, the oxidative stress-involved nephrotoxicity has been evidenced. However, herbal plants are the windfall for the humankind providing solution for most of the wellness breakdowns. Annona squamosa (AS) is one of such plants with enormous therapeutic and nutraceutical potencies. The main aspiration of the current investigation is to evaluate the nephroprotective ability of ethanolic extract of Annona squamosa (EEAS) leaves against paracetamol-induced nephrotoxicity using in vitro human embryonic kidney (HEK)-293 cells and in vivo experiments in Wistar rats through biochemical parameters, oxidative parameters, and histopathological findings.

Results: When HEK-293 cells were incubated with PCM, an increased cell death associated with alterations in the morphology of normal cells was observed. At variable concentrations, HEK-293 cells co-treated with PCM and EEAS extracts gave a significant improvement in cell growth on comparing with PCM treatment showing cytoprotective feature of EEAS with an $I_{50} 28.75 \mu \mathrm{g} / \mathrm{mL}$. In vivo nephroprotective property was assessed from the amount of blood urea nitrogen (BUN) along with creatinine and uric acid which were reduced $(P<0.001)$ within serum and compact levels of glutathione, catalase, and superoxide dismutase which were termed as GSH, CAT, and SOD, respectively, were increased $(P<0.001)$ in kidney tissue homogenate in the treated groups than the PCM alone group. Results were additionally supported by histopathological observations.
\end{abstract}

Conclusion: The results exhibited that EEAS has impending benefits against PCM-induced nephrotoxicity through in vitro and in vivo experiments.

Keywords: Nephrotoxicity, Paracetamol, Annona squamosa, HEK-293, Oxidative stress

\section{Background}

Acetaminophen, most commonly acknowledged with its generic name, paracetamol (PCM), is the last among the threesome of derivatives of para-aminophenol which was introduced at the end of the nineteenth century $[1,2]$. PCM is a potent analgesic as well as an antipyretic drug

\footnotetext{
* Correspondence: neelus1989@gmail.com

'Research Scholar, Jawaharlal Nehru Technological University Anantapur, Ananthapuramu, Andhra Pradesh, India

Full list of author information is available at the end of the article
}

with lesser side effects than aspirin [3]. Even today, there is exactly no alternative to this particular drug in terms of treating fever and mild pains in both children and adults. Since most of the pharmaceutical outlets do not require a prescription to trade with consumers, the abuse is very common. PCM is usually formulated with two strengths; regular strength of $325 \mathrm{mg}$ and higher strength of $500 \mathrm{mg}$ along with this higher dose PCM is also available. In large dose consumption, PCM is known to result in acute kidney and liver necrosis in mammalian species [4-6]. 
However, beyond therapeutic doses, unsafe behaviors arose, wherein the toxic $\mathrm{N}$-acetyl p-benzoquinone imine (NAPQI), which is an active intermediate metabolite during oxidation of PCM, depletes glutathione (GSH), leading to an increased amount of NAPQI reactive intermediates resulting in deprivation of tissues [7]. NAPQI is known to form covalent adducts with renal cellular proteins promoting the generation of higher levels of reactive oxygen species (ROS) and weakens the ATP, besides leading to apoptosis, promoting renal necrosis with relentless organ dysfunction [8-10].

Over and above, the kidneys are eminently vulnerable for such side effects since, the immense volume of blood course through and filtered in larger amounts aiding the removal of toxins. Nephrotoxicity drives an imbalance in body fluid along with electrolytes leading to hormonal imbalance as well [11]. Herein, we propose a plant source for the protective effect for PCM-induced nephrotoxicity.

Plant sources/medicinal plants are a boon for the human community. Ancient literature suggests numerous medicinal herbs that could alleviate or ease various ailments associated kidneys. To note, several plants have been experimented for their nephroprotective effect with an aid of drug-induced nephrotoxicity in animal models. Herbal extracts from Eurycoma longifolia [12], Curcuma longa [13-15], Pimpinella tirupatiensis [16], Allium sativum [17], Nigella sativa [14], and many more have proven their potency towards the abovementioned protective effects. Nonetheless, ethanolic extract of leaves of Annona squamosa (custard apple) remained unexplored for the same. Annona squamosa is a medium-sized, tropical tree growing up to $25 \mathrm{ft}$. large. The leaves are slender and oblong while the flowers are greenish yellow. The fruit is green and the pulp is yellowish white color with sweet in taste. Chemically, it contains an alkaloid, annonaine, and other constituents like flavonoids, glycosides, terpenes, and tetrahydro-isoquinloine alkaloids [18]. Literature survey demonstrated several pharmacological effects such as anti-diabetic [19], hepatoprotectivity [20], antibacterial [21], antioxidant [22], anti-ulcer [23], insecticidal [24], anti-inflammatory [25], and analgesic [26] activity of an interested plant.

As mentioned, since ethanolic extracts of leaves of Annona squamosa remain unexplored for a protective effect against PCM-induced nephrotoxicity, herein, screening was done with an aid of in vitro analysis using HEK-293 cells and in vivo analysis using Wistar rats. The study highlights the preliminary phytochemical screening of EEAS, the toxicity of EEAS by studying MTT [3-(4,5-dimethyl thiazol-2-yl)-2,5-diphenyl tetrazolium bromide] assay, and effect of EEAS on serum parameters such as BUN, creatinine, uric acid, and antioxidant enzymes levels in the kidney tissue along with histopathological studies.

\section{Methods}

\section{Chemicals}

Paracetamol was obtained from Waksman Selman Pharmaceuticals Pvt. Ltd., Anantapur, India. HEK-293 cells procured from NCCS, Pune. DMEM-high glucose, fetal bovine serum, MTT reagent, biochemical kits for quantification of serum, and antioxidant enzymes were procured from the Himedia Laboratories, Mumbai, India. Dimethyl sulfo-oxide (DMSO) and Silymarin were acquired from Sigma-Aldrich (St. Louis, USA). Ethanol (95\%) and other chemicals of analytical grade were utilized in the present study were obtained from standard pharmaceutical companies.

\section{Collection of plant solids}

Green leaves of Annona squamosa were possessed from fields of Madhavaram, Kadapa Dist, Andhra Pradesh. The identification and authentication of leaves were done by Dr. K. Madhava Chetty, Dept. of Botany, S.V. University, Tirupathi, with a voucher specimen no:0986.

\section{Preparation of ethanolic extract of Annona squamosa leaves}

The collected fresh plant material was washed thoroughly with tap water to get rid of filth and dried under shade till the leaves became brittle. Once dried, the leaves were crushed coarsely and powdered using a blender. The powder $(850 \mathrm{~g})$ was then subjected to defatting using petroleum ether in soxhlet for $18 \mathrm{~h}$ followed by drying. The dried powder was again packed within soxhlet for ethanol extraction for $72 \mathrm{~h}$ and until a clear solution is obtained in siphon tube and the yield of EEAS was $16.4 \%$. The overall methodology of the work is presented in Fig. 1.

\section{Cell viability and in vitro cytotoxicity Cytotoxicity analysis}

Human embryonic kidney 293 cell lines were utilized for the cell cytotoxicity analysis via the standard colorimetric method. The cells cultured in a 96-well plate with a cell density of 20,000 cells/wall, in the absence of the test agent was allowed for $24 \mathrm{~h}$. Test agents were added and subjected to incubation for $24 \mathrm{~h}$ at $37^{\circ} \mathrm{C}$ under $\mathrm{CO}_{2}$ atmosphere of $5 \%$. The spent media was then taken out and treated with a solution of MTT $(0.5 \mathrm{mg} / \mathrm{mL}$ of total volume) and again incubated for $3 \mathrm{~h}$. The cell viability was estimated by examining the conversion of MTT into purple formazon crystals by metabolically viable cells. The medium was then removed, and the obtained crystals were quantified for cell viability by dissolving in DMSO $(100 \mu \mathrm{L})$. ELISA was performed at $570 \mathrm{~nm}$ and the reference wavelength was set at $630 \mathrm{~nm}$ [27]. 


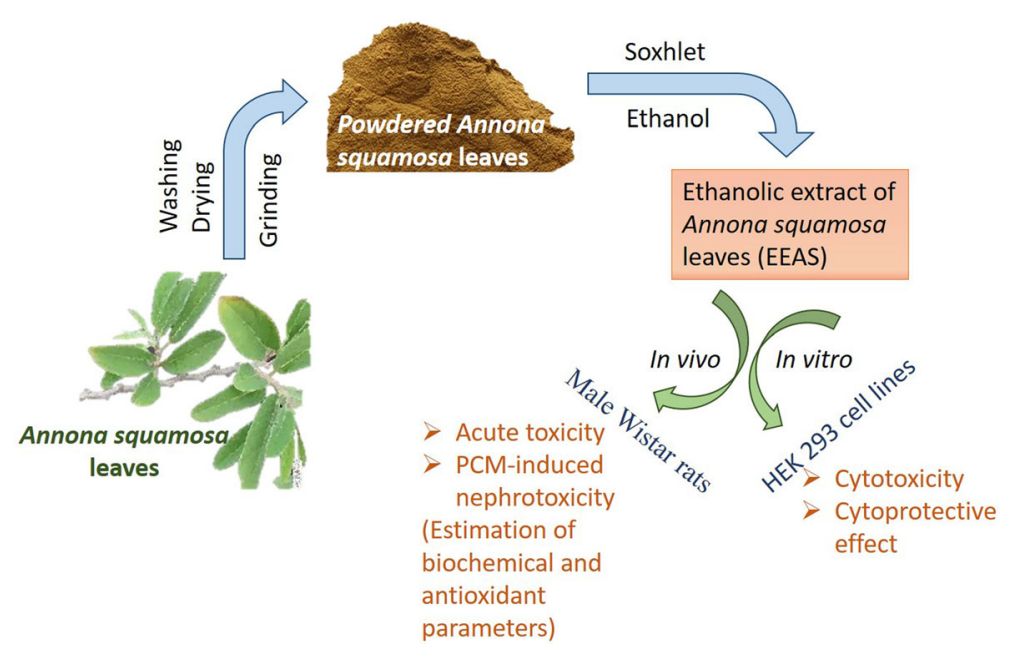

Fig. 1 Schematic representation of the overall methodology of the present work

\section{Cytoprotective analysis}

HEK cell line suspension of $200 \mu \mathrm{l}$ cells was taken in a 96-well plate at an appropriate cell density in the absence of a test agent and grew for $24 \mathrm{~h}$. To induce toxicity, a test compound, paracetamol with $\mathrm{IC}_{25}, \mathrm{IC}_{50}$, and $\mathrm{IC}_{75}$ concentrations were added and subjected to incubation for $24 \mathrm{~h}$ under a $\mathrm{CO}_{2}$ atmosphere of $5 \%$ at $37^{\circ} \mathrm{C}$. After incubation, spent media was taken out and MTT was added and incubated for $3 \mathrm{~h}$. With the addition of $100 \mu \mathrm{l}$ of solubilization solution, the MTT reagent was removed and allowed to dissolve MTT formazan crystals. With an ELISA reader, cytoprotective activity was analyzed.

\section{Animals and environmental conditions}

The animals used for the study were obtained from animal houses, and whole experiments were performed at the NGSM Institute of Pharmaceutical Sciences, Mangaluru, with a written consent. A total of 24 male Wistar rats with a weight of about 200-250 g were considered for the investigation and were quarantined and acclimatized for 14 days. Six rats were housed in every cage with ambient temperature $\left(21 \pm 3^{\circ} \mathrm{C}\right)$, controlled humidity $(50 \pm 10 \%)$, and $12 \mathrm{~h}$ of alternative light and dark cycles with an easy access to both food as well as water. The entire experimentations and protocols described in the present study were established by the Institutional Animal Ethical Committee (IAEC) of the NGSM Institute of Pharmaceutical Sciences, Mangaluru (NGSMIPS/IAEC/ MARCH-2019/126).

\section{Acute toxicity studies}

With an established OECD guideline 425, the acute toxicity of EEAS leaves was tested on various groups each with 10 rats. Every rat received different doses of 50,
$100,200,400,800,1000$, and $2000 \mathrm{mg} / \mathrm{kg}$ body weight. The number of deaths observed in every group was recorded for $48 \mathrm{~h}$. Up to $2000 \mathrm{mg} / \mathrm{kg}$, there was an absence of mortality and toxicity. Based on these studies, 200 and $400 \mathrm{mg} / \mathrm{kg}$ of EEAS were selected for future experimentations.

\section{Experimental design for PCM-induced nephrotoxicity}

The study was designed for 14 days, and the procedure was followed as in the previous reference [28]. Male Wistar rats were randomized into four groups of six rats in each group to achieve an average weight between and within the group not exceeding $\pm 20 \%$ of the average weights of all rats. The animal grouping was done in the following ways: Group I: (normal control) treated with normal saline p.o.; Group II: (disease control) treated with PCM, intraperitoneally at a dose of $200 \mathrm{mg} / \mathrm{kg}$ per day for 14 days; Groups III and IV: received EEAS at a dose of 200 and $400 \mathrm{mg} / \mathrm{kg}$ p.o., respectively, along with PCM $(200 \mathrm{mg} / \mathrm{kg})$ for 14 days.

\section{Estimation of biochemical and antioxidant parameters}

On 15th day, the fasted rats were euthanized with ketamine $(100 \mathrm{mg} / \mathrm{kg}$, intramuscularly) and heparinized tubes were used to collect the blood from the retro-orbital plexus. All 24 animals were used for each parameter at the end of the study. Blood plasma and serum were separated by centrifugation. The kidneys were quickly removed, washed with cold water followed by isotonic saline, and then blotted using a filter paper. Tissues were next homogenized using Tris-HC1 buffer $(0.1 \mathrm{M})$ of $\mathrm{pH}$ 7.4. The quantification of antioxidant enzymes was done using homogenate. Urea, creatinine, and uric acid in serum were determined using an analytical kit (Himedia Laboratories, 
Mumbai, India). Oxidative stress was estimated by measuring SOD, GSH, and catalase levels in the kidney tissue.

\section{Histopathological studies}

The kidney tissues of rats from each group were preserved in $10 \%$ formalin and processed with paraffin wax. For histopathological examination, very thin sections were considered for staining with hematoxylin followed by eosin for the clear analysis using a light microscope. Two sections from the individual sample were analyzed with the help of standardized protocol to identify chief morphological characteristics associated with PCM-induced nephrotoxicity. With microscope ocular of $22 \mathrm{~mm} \mathrm{FN}$, "high power field (40x)" $=0.237 \mathrm{~mm}^{2}$ area, hence by investigating at $10 \mathrm{HPF}$, a total of $2.37 \mathrm{~mm}^{2}$ / slide have been studied. The histological changes of glomerular, interstitial, tubular, and endothelial components were studied [29].

\section{Statistical analysis}

All the values were expressed as mean $\pm \operatorname{SEM}(n=6)$. The obtained data from various parameters was evaluated statistically using one-way analysis of variance (ANOVA) trailed by Tukey-Kramer multiple correlation tests, and the mean values were considered for the respective parameters.

\section{Results}

\section{Preliminary screening of phytochemicals}

The percent yield of EEAS was $16.40 \% \mathrm{w} / \mathrm{w}$. The qualitative phytochemical analysis of the extract showed the existence of high amounts of tannins, terpenoids, flavonoids along with phenolic compounds, moderate amounts of carbohydrates, alkaloids, anthraquinones, and lower amounts of steroids.

\section{MTT assay}

Cytotoxicity and cytoprotective activity of the test compound for PCM-induced toxicity were estimated by MTT assay with $15 \mu \mathrm{M}$ of silymarin (positive control), and the results are exposed in Fig. 2. Figure 2a, b depicts the cytotoxicity for PCM and EEAS, respectively, and Fig. 2c represents the cytoprotective feature of EEAS. Untreated cells were considered as control and STD refers to silymarin. From Fig. 2a, it is obvious that, with an increase in PCM concentration, the cell viability decreases indicating the cytotoxic effect of PCM at higher dosages. However, treatment with varied concentrations of EEAS did not pose a significant effect on the percent cell viability concluding the non-cytotoxic nature of EEAS. So, EEAS was considered as a cytoprotective compound on HEK 293 cells but not PCM alone due to its lower $\mathrm{IC}_{50}$ value. Further, the cytoprotective nature of EEAS against HEK 293 cell lines was evaluated at different dosages $(100,200$, and $400 \mu \mathrm{g} / \mathrm{ml})$ along with $\mathrm{IC}_{50}$ value of PCM $(28.75 \mu \mathrm{g} / \mathrm{ml})$. With a treatment of PCM alone, cell viability was significantly reduced $(P<0.001)$. The cytoprotective nature of combinational ones was dose-dependent, for the lower dose, cell viability increased to $17-18 \%$, for the medium dose, the increase was $6-8 \%$. Further with a higher dosage, the mean cell viability was around $85 \%$ endorsing the cytoprotective feature of EEAS. The direct microscopic observations of the untreated group, positive control, negative control, and EEAS+PCM-treated groups are displayed in Fig. 2d, i. The microscopic images are in good agreement with obtained cell viability.

\section{In vivo studies}

Effect of EEAS on BUN, creatinine, and uric acid on PCMinduced nephrotoxicity in rats

Quantification of serum biomarkers revealed a sharp rise in BUN, creatinine, and uric acid in the PCM alonetreated groups (Group II) on comparing with the normal group indicating the intraperitoneal administration of $200 \mathrm{mg} / \mathrm{kg} /$ day of PCM for 14 days prompted remarkable $(P<0.01)$ increase in all three conventional biomarker levels. Estimated levels of these parameters are tabulated in Table 1. However, in a dose-dependent fashion, the biomarkers level significantly $(P<0.001)$ decreased presenting the potency of EEAS towards nephrotoxicity.

\section{Effect of EEAS on antioxidant enzymes (GSH, SOD, and catalase) on PCM-induced nephrotoxicity in rats}

The kidney damage induced by $\mathrm{PCM}$-intoxicated rats and the effect of EEAS on GSH, SOD, and CAT is provided in Table 2. A considerable decline in levels of GSH, SOD, and CAT was observed for the PCM alonetreated group on comparing with the normal group. Contrarily, a significant raise $(P<0.001)$ was noted for antioxidant enzyme activities with an administration of EEAS $200 \mathrm{mg} / \mathrm{kg}$ and $400 \mathrm{mg} / \mathrm{kg}$, in the experimental model after inducing nephrotoxicity with PCM, indicating the efficiency of the EEAS with respect to the nephroprotective property.

\section{Histopathological studies}

Histopathological slides of the normal group, PCM alone group, and two used dosages of PCM and EEAS are presented in Fig. 3. The kidney tissue of normal rats showed no visible signs of degeneration or necrosis and was previously confirmed from biochemical and antioxidant results (Fig. 3a). Extensive kidney tissue degeneration along with tubular necrosis was noted in the PCM alone-treated rats (Fig. 3b). The rats which received 200 $\mathrm{mg} / \mathrm{kg}$ optimal EEAS showed a tubular pattern through reasonable necrosis and degranulation (Fig. 3c), whereas the rats which received $400 \mathrm{mg} / \mathrm{kg}$ EEAS exhibited very 


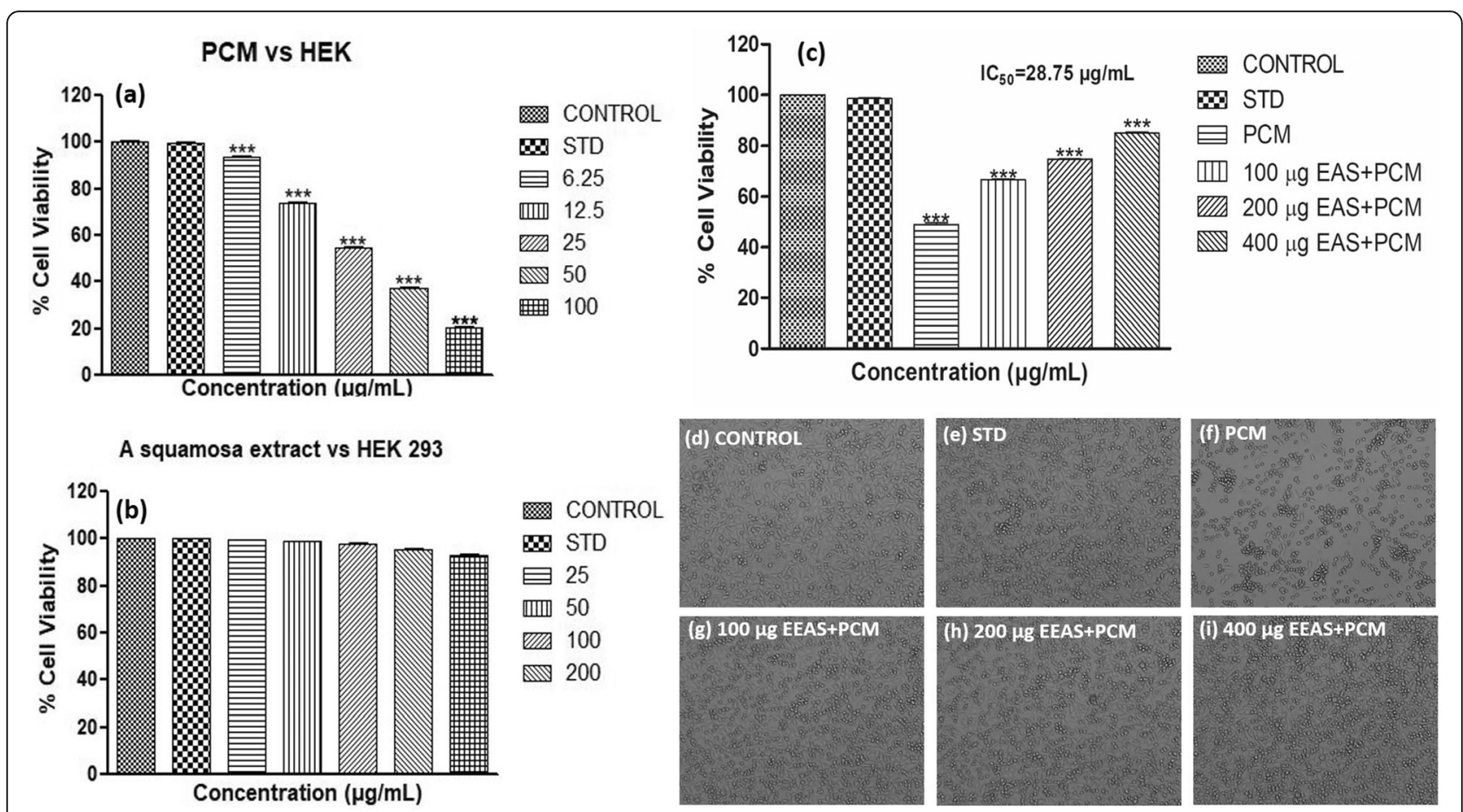

Fig. 2 Cytotoxic study for PCM and EEAS against HEK 293 cell lines (a and b, respectively), cytoprotective study for EEAS (c), and direct microscopic images of cytoprotective study (d to i)

mild swelling, necrosis, and cellular desquamation (Fig. 3d).

\section{Discussion}

At therapeutic doses, PCM is well thought-out to be a benign analgesic drug as well as an antipyretic drug. But, overdoses of it cause hepatotoxicity and nephrotoxicity in both humans and experimental animals. In critical overdosage or if daily dosage surpasses for an extended time, the standard conjugative metabolic pathway will be saturated and PCM is metabolized oxidatively by P450 (a diverse oxidase function system) to NAPQI. NAPQI possesses less half-life and is swiftly conjugated with glutathione and also with exhausted contents of cellular GSH. PCM-induced nephrotoxicity may cause tubular injury in the kidneys and is proved by phosphaturia, proteinuria of low molecular weight and can lead to severe renal failure which could be deadly in humans [1].
Before proceeding to in vivo nephrotoxicity studies, it is important to know the in vitro cell protective effect of the drug. For which MTT assay was carried out and significant percent cell viability was observed. MTT assay stands for enzymatic conversion of MTT into MTT formazan crystals which could be estimated by colorimetric method. The whole process was supported by succinate dehydrogenase produced from mitochondria of viable cells which depend on the respiration of mitochondria assessing the energy of the cell. In the current study, PCM-induced nephrotoxicity was treated with EEAS and found to be efficient enough to increase the percent cell viability.

With respect to in vivo nephrotoxicity studies, "gold standard" biomarkers were analyzed. The kidneys excrete BUN which is commonly found in liver proteins, diet, or tissue origin obtained from the breakdown of creatine. Creatinine is a derivative of endogenous tissue sources. In kidney ailments, the serum urea gets

Table 1 Effect of EEAS on BUN, creatinine, and uric acid on PCM-induced nephrotoxicity in rats

\begin{tabular}{llll}
\hline Group & BUN (mg/dl) & Creatinine (mg/dl) & Uric acid (mg/dl) \\
\hline Normal & $30.89 \pm 0.25$ & $5.12 \pm 0.008$ & $1.22 \pm 0.06$ \\
PCM alone & $72.17 \pm 0.192^{*}$ & $9.13 \pm 0.077^{*}$ & $2.05 \pm 0.13^{*}$ \\
$P C M+$ EEAS(200 mg/kg) & $54.2 \pm 0.044^{@ @ ~}$ & $3.13 \pm 0.112^{@ @}$ & $1.70 \pm 0.06^{@ @ ~}$ \\
$P C M+$ EEAS (400 mg/kg) & $38.5 \pm 0.03^{@ @ ~}$ & $4.57 \pm 0.82^{@ @ ~}$ & $1.23 \pm 0.03^{@ @ ~}$ \\
\hline
\end{tabular}

All values were expressed as mean \pm SEM, with six animals per group

*PCM-induced one compared with the normal one $(P<0.01)$

$@ @$ Two different experimental groups compared with the PCM-induced group $(P<0.001)$ 
Table 2 Effect of EEAS on GSH, SOD, and catalase on PCM-induced nephrotoxicity in rats

\begin{tabular}{llll}
\hline Group & GSH (nmol/g protein) & SOD (U/g protein) & Catalase (U/g protein) \\
\hline Normal & $68.16 \pm 0.24$ & $51.24 \pm 3.11$ & $55.01 \pm 0.53$ \\
PCM alone & $36.80 \pm 0.14^{*}$ & $29.17 \pm 1.58^{*}$ & $21.21 \pm 0.09^{*}$ \\
PCM + EEAS (200 mg/kg) & $43.36 \pm 0.73^{@ @}$ & $40.33 \pm 2.61^{@}$ & $38.58 \pm 0.19^{@ @}$ \\
PCM + EEAS (400 mg/kg) & $60.95 \pm 0.08^{@ @ ~}$ & $47.79 \pm 2.14^{@ @}$ & $49.54 \pm 0.14^{@ @ ~}$ \\
\hline
\end{tabular}

All values were expressed as mean \pm SEM with six animals in a group

*PCM-induced group compared with the normal group $(P<0.01)$

$@ @$ Two different experimental groups compared with the PCM-induced group $(P<0.001)$

deposited as the urea production rate exceeds the clearance rate. Any elevation of urea, creatinine, and also uric acid levels in serum are considered as the indexes of nephrotoxicity. But the concentration of BUN is regarded as a dependable kidney function predictor than creatinine. In the present study, rats having PCMinduced nephrotoxicity displayed a substantial $(P<0.01)$ rise in BUN, creatinine, and uric acid levels on comparing with the normal group. EEAS oral administration $(200$ and $400 \mathrm{mg} / \mathrm{kg})$ dosage considerably $(P<0.001)$ reduced BUN, creatinine, and uric acid levels in a dosedependent manner, which showed the potency of regeneration of renal cells. Along with serum biomarkers, administration of PCM nephrotoxic dose $(200 \mathrm{mg} / \mathrm{kg} /$ day $)$ has distorted kidney tissues oxidative status, causing oxidative stress by production of reactive oxygen and nitrogen species, respectively. These species further lead to necrosis of the renal tissue. Earlier research documentations exposed that GSH is the chief aqueoussoluble cellular nonenzymatic antioxidant serving as the first line of defense in fighting free radicals. This also plays a key role in detoxification by dropping hydrogen peroxide as well as lipid hydroperoxides directly into $\mathrm{H}_{2} \mathrm{O}$ and oxidized glutathione was formed [30]. Rats pre-treated with EEAS (200 and $400 \mathrm{mg} / \mathrm{kg}$ ) have evidently displayed the nephroprotective effect than critical PCM intoxicated rats. Mammal cells also have endogenous antioxidant enzymes like SOD and CAT which could perform detoxification of free radicals. These enzyme levels are controlled within the cells to make sure of upholding the redox balance of the body [31]. The results displayed in Table 2 have evidently showed a significant rise in the levels of SOD and CAT in EEAS pretreated rats, establishing a nephroprotective effect of considered leaves. The effective refurbishment of the activities of the abovementioned enzymes compared with

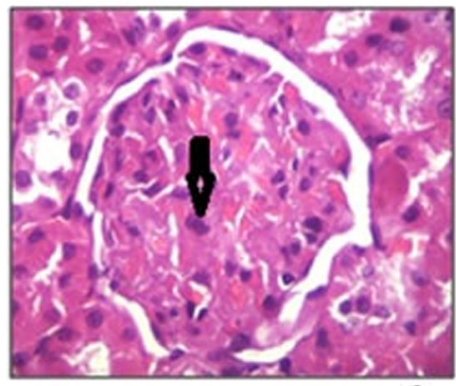

Figure 3 anno visible signs of degeneration or necrosis

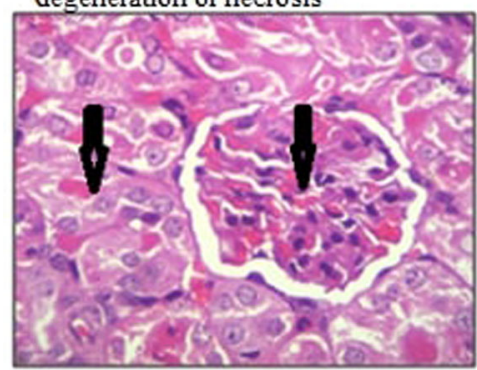

Figure 3 crepresents reasonable necrosis and degranulation

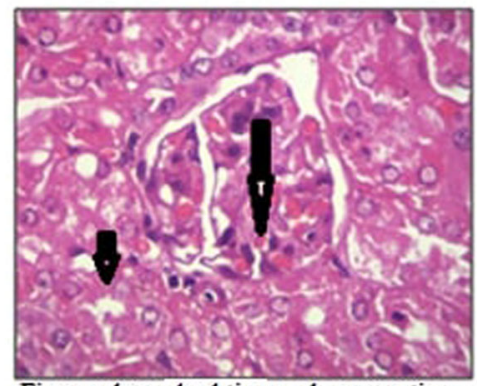

Figure $3 \mathrm{~b}$-marked tissue degeneration along with tubular necrosis

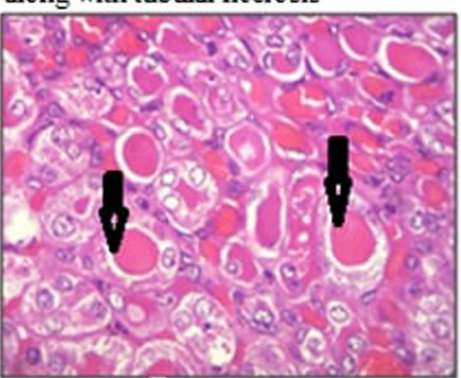

Figure 3drepresents very mild swelling, cellular desquamation

Fig. 3 Histopathological observations of the nephroprotective effect of EEAS against PCM-induced nephrotoxicity in rats where a control, $\mathbf{b}$ PCM alone, c PCM + EEAS $200 \mathrm{mg} / \mathrm{kg}$, and $\mathbf{d}$ PCM + EEAS $400 \mathrm{mg} / \mathrm{kg}$ 
PCM-intoxicated rats was probably because of the presence of the high levels of flavonoids, tannins, and polyphenols in ethanolic extract of Annona squamosa leaves [32]. When compared between a low dose and high dose of extract, EEAS $(400 \mathrm{mg} / \mathrm{kg}$ ) was said to be more effective in restoring serum biochemical parameters similar to normal and also increasing levels of antioxidant enzymes in tissue homogenate.

Similarly, in the present study, the histopathological analysis of PCM intoxicated kidney tissues in rats was acquired by sacrificing animals after $24 \mathrm{~h}$. The analysis displayed acute necrosis and tubular epithelium degeneration. These changes suggested the degeneration of cells along with acute tubular necrosis and were most related to histopathological change. An insignificant swelling or moderate necrosis (Fig. 3c, d) was observed in the pretreated EEAS (200 and $400 \mathrm{mg} / \mathrm{kg}$ ) and proved the agreeable renal tissue regeneration and also the results are in well agreement with the control.

\section{Conclusion}

The results demonstrated the nephroprotective effect of EEAS against PCM brought toxicity in both in vitro and in vivo models worked upon in HEK-293 cells and rat kidneys, respectively. Hereby, we propose the efficacy of EEAS as a safe nephroprotective agent.

\section{Abbreviations}

EEAS: Ethanolic extract of Annona squamosa; PCM: Paracetamol; HEK293: Human embryonic kidney cells; BUN: Blood urea nitrogen; MTT: 3-(4,5Dimethyl thiazol-2-yl)-2,5-diphenyl tetrazolium bromide; DMSO: Dimethyl sulfoxide; SOD: Superoxide dismutase; CAT: Catalase; GSH: Glutathione

\section{Acknowledgements}

The authors are grateful to Dr. D. Swarnalatha, Principal, Annamacharya College of Pharmacy, Rajampeta, and Dr. M. Vijay Kumar, NGSM Institute of Pharmaceutical Sciences, Mangaluru, for providing all facilities and their immense support for our work.

\section{Authors' contributions}

NS and DRP designed all the experiments. NS performed the experiment, analyzed the data, and wrote the manuscript. CSKB provided all the needed information. The authors read and approved the final manuscript.

\section{Funding}

Self-funding

\section{Availability of data and materials}

All the data and materials are available upon request.

\section{Ethics approval and consent to participate}

The animals used for the study were obtained from the animal house, and the whole experiment was performed at the NGSM Institute of Pharmaceutical Sciences, Mangaluru, with a written consent. Whole experiments and protocols described in the present study were established by the Institutional Animal Ethical Committee (IAEC) of NGSM Institute of Pharmaceutical Sciences, Mangaluru (NGSMIPS/IAEC/MARCH-2019/126).

\section{Consent for publication}

Not applicable.

\section{Competing interests}

The authors declare no conflicts of interest.

\section{Author details}

${ }^{1}$ Research Scholar, Jawaharlal Nehru Technological University Anantapur, Ananthapuramu, Andhra Pradesh, India. ²Department of Pharmaceutics, Annamacharya College of Pharmacy, Rajampeta, Andhra Pradesh, India.

${ }^{3}$ Krishna University, Machilipatnam, Andhra Pradesh, India.

Received: 23 September 2020 Accepted: 30 November 2020

Published online: 14 December 2020

\section{References}

1. Cekmen M, Ilbey Y, Ozbek E, Simsek A, Somay A, Ersoz C (2009) Curcumin prevents oxidative renal damage induced by acetaminophen in rats. Food Chem Toxicol 47(7):1480-1484

2. Black M (1984) Acetaminophen hepatotoxicity. Annual review of medicine 35(1):577-593

3. Coggon D, Langman M, Spiegelhalter D (1982) Aspirin, paracetamol, and haematemesis and melaena. Gut 23(4):340-344

4. Fisher ES, Curry SC (2019) Evaluation and treatment of acetaminophen toxicity. Adv Pharmacol 85:263-272

5. Mour G, Feinfeld DA, Caraccio T, McGuigan M (2005) Acute renal dysfunction in acetaminophen poisoning. Ren Fail 27(4):381-383

6. Davidson D, Eastham W (1966) Acute liver necrosis following overdose of paracetamol. Br Med J 2(5512):497

7. Bessems JG, Vermeulen NP (2001) Paracetamol (acetaminophen)-induced toxicity: molecular and biochemical mechanisms, analogues and protective approaches. Crit Rev Toxicol 31(1):55-138

8. Ko J-W, Shin J-Y, Kim J-W, Park S-H, Shin N-R, Lee I-C, Shin I-S, Moon C, Kim S-H, Kim S-H (2017) Protective effects of diallyl disulfide against acetaminophen-induced nephrotoxicity: a possible role of CYP2E1 and NFkB. Food Chem Toxicol 102:156-165

9. Haidara MA, Al-Ani B, Eid RA, Mohammed ME, Al-Hashem F, Dallak M (2020) Acetaminophen induces alterations to the renal tubular ultrastructure in a rat model of acute nephrotoxicity protected by resveratrol and quercetin. Int J Morphol 38(3):585-591

10. Orji BO, Obi FO, Modo EU, Osibemhe M, Otitolaiye CA (2020) Amelioration of paracetamol-induced nephrotoxicity in mice by aqueous extract from the calyx of Hibiscus sabdariffa Linn. Biokemistri 32(1)23-34

11. Naughton CA (2008) Drug-induced nephrotoxicity. Am Fam Phys 78(6):743-750

12. Chinnappan SM, George A, Thaggikuppe P, Choudhary Y, Choudhary VK, Ramani Y, Dewangan R (2019) Nephroprotective effect of herbal extract of eurycoma longifolia on paracetamol-induced nephrotoxicity in rats. Evid Based Complement Altern Med 2019:4916519. https://doi.org/10.1155/2019/ 4916519

13. Khoursandi L, Ourazizadeh M (2008) Protective effect of Curcuma longa extract on acetaminophen induced nephrotoxicity in mice

14. Mohebbati R, Shafei MN, Soukhtanloo M, Roshan NM, Rad AK, Anaeigoudari A, Hosseinian S, Karimi S, Beheshti F (2016) Adriamycin-induced oxidative stress is prevented by mixed hydro-alcoholic extract of Nigella sativa and Curcuma longa in rat kidney. Avicenna J Phytomed 6(1):86

15. Venkatesan N, Punithavathi D, Arumugam V (2000) Curcumin prevents adriamycin nephrotoxicity in rats. Br J Pharmacol 129(2):231-234

16. Palani S, Raja S, Kumar RP, Jayakumar S, Kumar BS (2009) Therapeutic efficacy of Pimpinella tirupatiensis (Apiaceae) on acetaminophen induced nephrotoxicity and oxidative stress in male albino rats. Int J PharmTech Res 1(3):925-934

17. Gulnaz H, Tahir M, Munir B, Sami W (2010) Protective effects of garlic oil on acetaminophen induced nephrotoxicity in male albino rats. Biomedica 26(7):9-15

18. Pandey N, Barve D (2011) Phytochemical and pharmacological review on Annona squamosa Linn. Int J Res Pharm Biomed Sci 2(4):1404-1412

19. Tomar RS, Sisodia SS (2012) Antidiabetic activity of Annona squamosa L. in experimental induced diabetic rats. Int J Pharm Biol Arch 3:1492-1495

20. Raj DS, Vennila JJ, Aiyavu C, Panneerselvam K (2009) The hepatoprotective effect of alcoholic extract of Annona squamosa leaves on experimentally induced liver injury in Swiss albino mice. Int J Integr Biol 5(3):182-186

21. Kachhawa J, Sharma N, Tyagi S, Sharma K (2012) Screening of stem bark methanol extract of Annona squamosa for antibacterial activity. Int J Curr Pharm Res 4(1):48-50

22. Shirwaikar A, Rajendran K, Kumar CD (2004) In vitro antioxidant studies of Annona squamosa Linn. leaves. Indian J Exp Biol. 42(8):803-807

23. Palanisamy A, Permual P, Billa $V$ (2011) Anti ulcer activity of ethanolic extract of Annona squamosa leaves. Int J Pharm Res Dev 4(1):162-167 
24. Kumar J, Rekha T, Devi S, Kannan M, Jaswanth A, Gopal V (2010) Insecticidal activity of ethanolic extract of leaves of Annona squamosa. J Chem Pharm Res 2(5):177-180

25. Pardhasaradhi B, Reddy M, Ali AM, Kumari AL, Khar A (2004) Antitumour activity of Annona squamosa seed extracts is through the generation of free radicals and induction of apoptosis. Indian J Biochem Biophys 41:167-172

26. Manvi FV, Nanjawade BK, Sanjiv S (2011) Pharmacological screening of combined extract of Annona squamosa and Nigella sativa. Int J Pharm Bio Sci. 2(2):520-529

27. Singh MP, Chauhan AK, Kang SC (2018) Morin hydrate ameliorates cisplatininduced ER stress, inflammation and autophagy in HEK-293 cells and mice kidney via PARP-1 regulation. Int Immunopharmacol 56:156-167

28. Al Tayib O, El Badwi S (2016) Assessment of ameliorative effects of aqueous extracts of Moringa oleifera on acetaminophen induced nephrotoxicity in rats. IOSR J Human Soc Sci 21(9):1-7

29. Palani S, Raja S, Karthi S, Archana S, Kumar BS (2010) In vivo analysis of nephro \& hepato protective effects and antioxidant activity of Madhuca longifolia against acetaminophen-induced toxicity \& oxidative stress. J Pharm Res 3(1):9-16

30. Kim S-H, Lee I-C, Baek H-S, Shin I-S, Moon C, Bae C-S, Kim S-H, Kim J-C, Kim $\mathrm{H}-\mathrm{C}$ (2014) Mechanism for the protective effect of diallyl disulfide against cyclophosphamide acute urotoxicity in rats. Food Chem Toxicol 64:110-118

31. Lee IC, Kim SH, Baek HS, Moon C, Kim SH, Kim YB, Yun WK, Kim HC, Kim JC (2015) Protective effects of diallyl disulfide on carbon tetrachloride-induced hepatotoxicity through activation of Nrf2. Environ Toxicol 30(5):538-548

32. Kalidindi N, Thimmaiah NV, Jagadeesh NV, Nandeep R, Swetha S, Kalidindi B (2015) Antifungal and antioxidant activities of organic and aqueous extracts of Annona squamosa Linn. leaves. J Food Drug Anal 23(4):795-802

\section{Publisher's Note}

Springer Nature remains neutral with regard to jurisdictional claims in published maps and institutional affiliations.

\section{Submit your manuscript to a SpringerOpen ${ }^{\circ}$ journal and benefit from:}

- Convenient online submission

- Rigorous peer review

- Open access: articles freely available online

High visibility within the field

- Retaining the copyright to your article

Submit your next manuscript at $\boldsymbol{\nabla}$ springeropen.com 